\title{
LA LEY SOBRE BASES GENERALES DEL MEDIO AMBIENTE
}

\section{Sergio Gómez Núñez}

\section{Profesor Titular de Derecho Civil}

\section{Escuela de Derecho Universidad Católica del Norte}

La actividad industrial de un país generalmente viene asociada a una transformación de bienes o una obtención de recursos provenientes de la naturaleza. Esta gestión importa, en la mayoría de estos casos, una alteración más o menos importante del medio en que se desarrolla, impactando el entorno de una manera más o menos sostenida.

Así, por ejemplo, ocurre con la industria pesquera, forestal, ganadera, agrícola, minera, manufacturera, el transporte aéreo, terrestre o marítimo y, en fin, con casi toda la creciente y sofisticada actividad del hombre actual.

Debido al incremento del deterioro que esta actividad ha venido causando al medio ambiente y a la previsible escasez de productos básicos renovables, los países han comenzado a desarrollar diversas barreras y controles a la indiscriminada actividad industrial que se había venido desarrollando, de tal manera de poder detener, impedir, incluso, revertir, tal orden de cosas.

Actualmente la activa preocupación de los países por el medio ambiente no sólo constituye una natural forma de abordar seriamente el problema que cada uno de ellos enfrenta, sino que es la manera más viable para poder insertarse en la comunidad internacional.

Nuestro país no podía, en su calidad de productor de riquezas básicas y productos primarios, y como exportador de los mismos, mantenerse al margen de esta corriente internacional. Muy por el contrario, ha tenido una actitud decididamente receptiva a los requerimientos y estándares de los países más desarrollados y ha buscado traducirla en normas nacionales.

Así, por lo demás, se encuentra expresado en la Constitución Política de Chile, cuyo Capítulo Tercero referido a los Derechos y Deberes Constitucionales, artículo 19 establece:

La Constitución asegura a todas las personas:

8.- El derecho a vivir en un medio ambiente libre de contaminación. Es deber del Estado velar para que este derecho no sea afectado y tutelar la preservación de la naturaleza.

La ley podrá establecer restricciones específicas al ejercicio de determinados derechos o libertades para proteger el medio ambiente."

En este contexto, la búsqueda óptima de la legislación más adecuada no ha resultado fácil, pues son múltiples los intereses en juego y diversos los caminos que escoger 
para resolverlos, a lo que hay que agregar, además, la necesidad virtual de desmontar una diversidad de normas que, a lo largo de casi ochenta años, se han dictado-de las que actualmente se encuentran en vigencia sobre 800-, a lo que debe sumarse la innumerable cantidad de organismos y autoridades que participan de dicho control, lo que obstaculiza naturalmente el propósito que se ha perseguido.

Pese a todo, se ha ido generando un alto grado de preocupación por la preservación de la naturaleza y sus recursos, interés que no sólo se ha observado en determinados grupos, conocidos como ecologistas, sino que ha alcanzado también a los gobiernos y organismos internacionales. La búsqueda del Desarrollo Sustentable; esto es, el proceso de mejoramiento sostenido y equitativo de la calidad de vida de las personas, fundado en medidas apropiadas y conservación y protección del medio ambiente, de manera de no comprometer las expectativas de las generaciones futuras (art. $1^{\circ}$ de la Ley en comento) constituye uno de los propósitos fundamentales perseguidos por el legislador.

El paso más importante en tal sentido se ha dado en la búsqueda de una normativa general, cuyo proyecto de ley propuesto por el Gobierno, y que estuvo antecedida del aporte de Universidades, profesionales, industriales, organismos ecologistas, persigue proyectar una legislación sobre el medio ambiente, constituida por una Ley General y diversas otras disposiciones de ley o reglamentarias que establecieran un todo coherente y único que hiciera posible un desarrollo industrial en pleno respeto del medio ambiente y control más eficaz en caso de su inobservancia.

Recientemente, y luego de dos años de tramitación en el Congreso Nacional, se ha dado el primero de dichos pasos al ser promulgada y publicada la primera y más importante de dichas normas legales: la Ley sobre Bases Generales del Medio Ambiente. El análisis de esta ley lo haremos en las líneas siguientes.

\section{Ley sobre Bases Generales del Medio Ambiente.}

El 9 de marzo de 1994 fue publicada en el Diario Oficial la Ley $n^{\circ} 19.300$, sobre Bases Generales del Medio Ambiente, la que comenzó a regir con esa misma fecha, salvo algunas disposiciones cuya vigencia se establece para más adelante o sujeta a la reglamentación que deba dictarse.

La ley está dividida en cinco títulos más un título final, con 92 artículos más siete artículos transitorios. Su publicación contiene, además, el informe del Tribunal Constitucional que declaró el artículo 49 inconstitucional, así como algunos preceptos de los artículos 50 y 51 del texto legal, que por lo mismo, no forman parte de la ley. Es, en todo caso, una ley evidentemente más breve que las dictadas en algunos otros países latinoamericanos.

Se trata de lo que se denomina una ley "marco", esto es, contempla las disposiciones fundamentales por las que ha de regirse toda disposición legal que se dicte sobre el tema, dejando que las normas más detalladas sean materia de reglamentos.

Ha recogido uno de los varios principios que se estatuyen para hacer efectiva su aplicación, y cuya premisa es: "el que contamina paga". Así queda establecido en su ar-

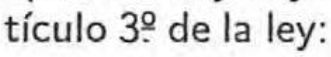

"Sin perjuicio de las sanciones que señale la ley, todo el que culposa o dolosamente cause daño al medio ambiente, estará obligado a repararlo materialmente, a su 
costo, si ello fuera posible, e indemnizarlo en conformidad a la ley".

La ley establece el procedimiento para que puedan llevarse a cabo los proyectos o actividades industriales que pudieran afectar el medio ambiente, y que se describen en el artículo 10 de la leý, denominados Evaluación de Impacto Ambiental así como los organismos que participan. Al respecto, se establece la denominada "ventanilla única", pues todas las presentaciones deben hacerse ante la Comisión Regional del Medio Ambiente de la Región en que se realizarán las obras materiales o ante la Dirección Ejecutiva de la Comisión Nacional del Medio Ambiente si abarca distintas regiones.

Asimismo, se contempla la dictación de Normas Primarias y Secundarias de Calidad Ambiental y se establece la responsabilidad por Daño Ambiental.

\section{Disposiciones Generales y Finalidad.}

El Título I "Disposiciones Generales", en su artículo $1^{\circ}$, se inicia con una declaración que enmarca el ámbito de aplicación de la ley y lo conjuga ampliamente con el precepto constitucional ya transcrito:

"El derecho a vivir en un medio ambiente libre de contaminación, la protección del medio ambiente, la preservación de la naturaleza y la conservación del patrimonio ambiental se regularán por las disposiciones de esta ley, sin perjuicio de lo que otras normas legales establezcan sobre la materia"

Con buen criterio la ley trae un glosario de definiciones legales de términos empleados en materia de medio ambiente, de forma que en adelante deberemos atenernos a la definición legal que define ciertas expresiones de uso común.

Así, el Medio Ambiente es el sistema global constituido por elementos naturales y artificiales de naturaleza física, química o biológica, socioculturales y sus interacciones, en permanente modificación por la acción humana o natural y que rige y condiciona la existencia y desarrollo de la vida en sus múltiples manifestaciones.

Dentro de este contexto constituye Medio Ambiente Libre de Contaminación, aquél en el que los contaminantes se encuentran en concentraciones y períodos inferiores a aquéllos susceptibles de constituir un riesgo a la salud de las personas, a la calidad de vida de la población, a la preservación de la naturaleza o a la conservación del patrimonio ambiental.

La Preservación de la Naturaleza es el conjunto de políticas, planes, programas, normas y acciones destinadas a asegurar la mantención de las condiciones que hacen posible la evolución y el desarrollo de las especies y de los ecosistemas del país. Y la Protección del Medio Ambiente el conjunto de políticas, planes, programas, normas y acciones destinados a mejorar el medio ambiente y a prevenir y controlar su deterioro.

La Conservación del Patrimonio Ambiental es el uso y aprovechamiento racionales o la reparación, en su caso, de los componentes del medio ambiente, especialmente aquellos propios del país que sean únicos, escasos o representativos, con el objeto de asegurar su permanencia y su capacidad de regeneración.

Otras definiciones están referidas a : biodiversidad o diversidad biológica, contaminación, contaminante, daño ambiental, declaración de impacto ambiental, educación ambiental, estudio de impacto ambiental, evaluación de impacto ambiental, impacto ambiental, línea base, norma primaria de calidad ambiental, norma secundaria de cali- 
dad ambiental, normas de emisión, recursos naturales, reparación, zona latente y zona saturada, algunas de cuyas definiciones se incluyen más adelante.

\section{Organismos vinculados al medio Ambiente dispuestos por la ley}

\section{1.-Organización a Nivel Nacional}

\section{a) Comisión Nacional de Medio Ambiente (CONAMA)}

El máximo organismo que la ley contempla es la Comisión Nacional del Medio Ambiente, (CONAMA) constituida como servicio público dependiente directamente del Presidente de la República y cuyas funciones están establecidas en el artículo 70 de la ley.

Le corresponden las siguientes funciones:

a) Proponer al Presidente de la República las políticas ambientales del gobierno;

b) Informar periódicamente al Presidente de la República sobre el cumplimiento y aplicación de la legislación vigente en materia ambiental;

c) Actuar como órgano de consulta, análisis, comunicación y coordinación en materias relacionadas con el medio ambiente;

d) Mantener un sistema nacional de información ambiental, desglosada regionalmente, de carácter público;

e) Administrar el sistema de evaluación de impacto ambiental a nivel nacional, coordinar el proceso de generación de las normas de calidad ambiental y determinar los programas para su cumplimiento;

f) Colaborar con las autoridades competentes en la preparación, aprobación y desarrollo de programas de educación y difusión ambiental, orientados a la creación de una conciencia nacional sobre la protección del medio ambiente, la preservación de la naturaleza y la conservación del patrimonio ambiental, y a promover la participación ciudadana en estas materias;

g) Coordinar a los organismos competentes en materias vinculadas con el apoyo internacional a proyectos ambientales, y ser, junto con la Agencia de Cooperación Internacional del Ministerio de Planificación y Cooperación, contraparte nacional en proyectos ambientales con financiamiento internacional;

h) Financiar proyectos y actividades orientados a la protección del medio ambiente, la preservación de la naturaleza y la conservación del patrimonio ambiental, y

i) Asumir todas las demás funciones y atribuciones que la ley le encomiende.

\section{b) Consejo Directivo}

La Dirección Superior de la Comisión Nacional del Medio Ambiente corresponde a un Consejo Directivo el que estará integrado por: 
-El Ministro Secretario General de la Presidencia, que lo presidirá

-El Ministro de Economía, Fomento y Reconstrucción

-El Ministro de Obras Públicas

-El Ministro de Agricultura

-El Ministro de Bienes Nacionales

-El Ministro de Salud

-El Ministro de Minería

-El Ministro de Vivienda y Urbanismo

-El Ministro de Transporte y Telecomunicaciones

-El Ministro de Planificación y Cooperación.

Las funciones del Consejo Directivo establecidas en el artículo 72 de la ley, señalan que corresponde a él:

a) Ejercer y hacer cumplir las funciones enunciadas en el artículo 70 de esta ley, (es decir al CONAMA);

b) Velar por la coordinación en materia ambiental, entre los ministerios, organismos y servicios públicos;

c) Velar por el cumplimiento de los acuerdos y políticas establecidos por la Comisión;

d) Proponer al Presidente de la República proyectos de ley y actos administrativos relativos a materias ambientales, sin perjuicio de las funciones propias de otros organismos públicos;

e) Promover la coordinación de las tareas de fiscalización y control que desarrollan, en materia ambiental, los diversos organismos públicos y municipalidades;

f) Aprobar el programa anual de actividades y el proyecto de presupuesto de la Comisión y sus modificaciones;

g) Aprobar las bases generales de administración de los recursos destinados al financiamiento de proyectos y actividades orientados a la protección del medio ambiente, la preservación de la naturaleza y la conservación del patrimonio ambiental;

h) Adquirir, enajenar, gravar y administrar toda clase de bienes, para el cumplimiento de sus fines propios;

i) Delegar parte de sus funciones y atribuciones en el Presidente, Director Ejecutivo, en los demás funcionarios de la Comisión y, para materias específicas, en Comités que al efecto constituya;

j) Aprobar la organización interna de la Comisión y sus modificaciones; a propuesta del Director Ejecutivo;

k) Adoptar todos los acuerdos que sean necesarios para el buen funcionamiento de la Comisión;

1) Conocer del recurso de reclamación en materia de estudio de Impacto Ambiental en el caso del artículo 20, oyendo al Consejo Consultivo; y

II) Asumir todas las demás funciones y atribuciones que la ley le encomiende. 


\section{c) Dirección Ejecutiva}

La administración de la Comisión Nacional de Medio Ambiente corresponde al Director Ejecutivo quien es el Jefe Superior del Servicio y tiene su representación legal. Es designado por el Presidente de la República.

Las funciones del Director Ejecutivo están establecidas en el artículo 76 de la ley y le corresponde las siguientes:

a) La administración superior del Servicio;

b) Cumplir y hacer cumplir los acuerdos e instrucciones del Consejo Directivo, y realizar los actos y funciones que éste le delegue en el ejercicio de sus atribuciones;

c) Requerir de los organismos del Estado la información y antecedentes que estime hecesarios y que guarden relación con sus respectivas esferas de competencia;

d) Proponer al Consejo Directivo el programa anual de actividades del Servicio; así como cualesquiera otras materias que requieran de su estudio o resolución;

e) Preparar el proyecto de presupuesto de la Comisión para someterlo al Consejo Directivo, y proponer las modificaciones presupuestarias que se requieran;

f) Proponer al Consejo Directivo la organización interna del Servicio y sus modificaciones;

g) Asistir con derecho a voz, a las sesiones del Consejo Directivo;

h) Informar periódicamente al Consejo Directivo acerca de la marcha de la institución y del cumplimiento de sus acuerdos e instrucciones;

i) Designar y contratar personal, y poner término a sus servicios, sin perjuicio de las atribuciones que en esta materia se le confieren al Consejo Directivo;

j) Designar a los Directores Regionales de las Comisiones Regionales del Medio Ambiente, en conformidad a lo dispuesto en el artículo 80;

k) En cumplimiento de sus funciones, adquirir y administrar bienes muebles, así como celebrar los actos y contratos que sean necesarios para tal cumplimiento;

1) Conocer el recurso de reclamación en materia de Declaración de Impacto Ambiental en el caso del artículo 20 de la presente ley;

II) Administrar los recursos destinados al financiamiento de proyectos y de actividades orientados a la protección del medio ambiente, la preservación de la naturaleza y la conservación del patrimonio ambiental, conforme a las bases generales fijadas por el Consejo Directivo;

m) Delegar parte de sus funciones y atribuciones en funcionarios del Servicio;

n) Vincularse técnicamente con los organismos internacionales dedicados al tema del medio ambiente, sin perjuicio de las atribuciones que le corresponden al Ministerio de Relaciones exteriores;

ñ) Conferir poder a abogados habilitados para el ejercicio de la profesión, aun cuando no sean funcionarios del Servicio, con las facultades de ambos incisos del artículo $7^{\circ}$ del Código de procedimiento Civil, y 
o) En general, dictar las resoluciones y ejercer las demás facultades legales y reglamentarias que sean necesarias para la buena marcha del Servicio.

\section{d) Consejo Consultivo}

Asimismo habrá un Consejo Consultivo de la Comisión Nacional del Medio Ambiente, presidido por el Presidente de la Comisión integrado por:

- Dos científicos, propuestos en quina por el Consejo de Rectores de las Universidades Chilenas;

- Dos representantes de organizaciones no gubernamentales (ONG) sin fines de lucro que tengan por objeto la protección del medio ambiente;

- Dos representantes de centros académicos independientes que estudien o se ocupen de materias ambientales;

- Dos representantes del empresariado, propuestos en quina por la organización empresarial de mayor representatividad en el país;

- Dos representantes de los trabajadores, propuestos en quina por la organización sindical de mayor representatividad en el país, y

- Un representante del Presidente de la República.

Sus funciones se encuentran detalladas en el artículo 79 de la ley, que establece que le corresponde al Consejo Consultivo absolver las consultas que le formule el Consejo Directivo, emitir opiniones sobre los anteproyectos de la ley y decretos supremos que fijen normas de calidad ambiental, de preservación de la naturaleza y conservación del patrimonio ambiental, planes de prevención y de descontaminación, regulaciones especiales de emisiones y normas de emisión que les sean sometidos a su conocimiento, y ejercer todas las demás funciones que le encomiende el Consejo Directivo y la ley.

La Comisión del Medio Ambiente se desconcentrará territorialmente a través de las Comisiones Regionales del Medio Ambiente.

\section{2.-Organización a Nivel Regional}

\section{a) Comisiones Regionales del Medio Ambiente} Ambiente.

En Cada Región existirá un Director Regional de la Comisión Nacional del Medio

Esta Comisión Regional del Medio Ambiente estará integrada por:

- El Intendente Regional, quien la presidirá

- Los Gobernadores de la región

- Los Secretarios Ministeriales correspondiente a los Ministerios que integran el Consejo Directiva de la Comisión Nacional de Medio Ambiente .

- Cuatro Consejeros regionales elegidos por el Consejo en una sola votación

- El Director Regional de la Comisión Regional del Medio Ambiente, quien actuará como secretario. 
Según lo dispone el artículo 85 de la ley, a la Comisión Regional del Medio Ambiente, le corresponde coordinar la gestión ambiental en el nivel regional, y cumplir las demás funciones que le encomiende la ley. Además deben establecer sistemas que aseguren una adecuada participación de las municipalidades y de las organizaciones sociales de la región, en todas aquellas materias referidas al medio ambiente.

\section{b) Comité Técnico}

Habrá además un Comité Técnico integrado por el Director Regional del Medio Ambiente, quien lo presidirá y por los Directores Regionales de los Servicios Públicos que tengan competencia en materia de medio ambiente, incluido el Gobernador Marítimo correspondiente.

\section{c) Consejo Consultivo Regional de Medio Ambiente}

Asimismo habrá en cada Región un Consejo Consultivo Regional de Medio Ambiente, integrạdo por:

- Dos científicos;

- Dos representantes de organizaciones no gubernamentales sin fines de lucro que tengan por objeto la protección o estudio del medio ambiente;

- Dos representantes del empresariado;

- Dos representantes de los trabajadores, y

- Un representante del Intendente Regional.

Conforme lo dispone el artículo 83 de la ley, corresponderá al Consejo Consultivo Regional absolver las consultas que le formule la Comisión Regional del Medio Ambiente y ejercer todas las demás funciones que le encomiende la ley.

\section{Sistemas de Evaluación de Impacto Ambiental}

Bajo el Título II de la ley, referida a los Instrumentos de Gestión Ambiental, la educación y la investigación constituyen dos de los elementos más importantes para una adecuada toma de conciencia de los problemas ambientales. Otros instrumentos de gestión ambiental lo constițuyen los sistemas de Evaluación de Impacto Ambiental.

Se entiende como Evaluación de Impacto Ambiental el procedimiento a cargo de la Comisión Regional o ante la Dirección Ejecutiva de la Comisión Nacional del Medio Ambiente si abarca más de una región, que, sobre la base de un Estudio o declaración de Impacto Ambiental, determina si el impacto ambiental de una actividad o proyecto se ajusta a las normas vigentes.

Como se ha expresado anteriormente, los proyectos y actividades industriales a que se refiere el artículo 10 de la ley, sólo podrán ejecutarse o modificarse previa evaluación de su impacto ambiental.

Para ello se hace necesario presentar un Estudio de Impacto Ambiental que es el documento que describe pormenorizadamente las características de un proyecto o actividad que se pretenda llevar a cabo o su modificación. Debe proporcionar antecedentes 
fundados para la predicción, identificación e interpretación de su impacto ambiental y describir la o las acciones que ejecutará para impedir o minimizar sus efectos significativamente adversos.

Todos los permisos o pronunciamientos de carácter ambiental que deban o puedan emitir los organismos del Estado serán coordinados y obtenidos a través de la Comisión Regional o Nacional del Medio Ambiente.

El artículo 11 señala en qué casos los proyectos o actividades a que se refiere el artículo 10 de la ley generan efectos, características o circunstancias que obligan a presentar Estudios de Impacto Ambiental. De igual manera las materias que debe abarcar dicho estudio (art. 12 de la ley).

En todo caso, la elaboración y calificación del estudio de Impacto Ambiental deberá sujetarse a un Reglamento que deberá ser dictado por Decreto Supremo. Este no se ha dictado aún y deberá señalarse en él el procedimiento administrativo para su tramitación.

La autoridad dispondrá de un plazo de 120 días para pronunciarse sobre el Estudio de Impacto Ambiental sin considerar sus prórrogas. Si no lo hace dentro de dicho plazo, considerando las prórrogas, se le tendrá por calificado favorablemente.

La ley contempla la posibilidad que el responsable del proyecto o actividad presente, junto con el Estudio de Impacto Ambiental, una póliza de seguro que cubra el riesgo por daño al medio ambiente por un plazo de 120 días, en cuyo caso podrá obtener una autorización provisoria para iniciar el proyecto o actividad, bajo su propia responsabilidad, sin perjuicio de lo que la autoridad resuelva en definitiva ( art. 15 inciso $2^{\circ}$ ).

Si no se requiere elaborar un Estudio de Impacto Ambiental, el interesado puede presentar una Declaración de Impacto Ambiental, bajo la forma de una declaración jurada, expresando que cumple con las normas ambientales vigentes. La autoridad deberá pronunciarse respecto de ella en un plazo máximo de 60 días.

La Declaración de Impacto Ambiental que es el documento descriptivo de una actividad o proyecto que se pretende realizar, o de las modificaciones que se le introducirán, otorgado bajo juramento por el respectivo titular, cuyo contenido permite al organismo competente evaluar si su impacto ambiental se ajusta a las normas ambientales vigentes.

La Ley Sobre Bases Generales del Medio Ambiente contempla la participación de la comunidad en el procedimiento de evaluación de Impacto Ambiental, ya que será necesario que el interesado publique en el Diario Oficial y en un diario de la capital de la Región un extracto del Estudio de Impacto Ambiental, publicación que debe hacerse dentro de los 10 días siguientes a la presentación.

Las organizaciones ciudadanas con personalidad jurídica, por intermedio de sus representantes y las personas naturales directamente afectadas pueden imponerse del contenido del estudio y demás antecedentes y formular observaciones dentro del plazo de 60 días contados desde la publicación e incluso recursos de reclamación ante la autoridad superior si sus observaciones no han sido debidamente ponderadas. 


\section{Normas de Calidad Ambiental, de la Preservación de la Naturaleza y Conser- vación del Patrimonio Ambiental y Normas de Emisión.}

La ley ha dispuesto que existirán normas Primarias y Secundarias de Calidad Ambiental que se fijarán por la autoridad, las que tendrán aplicación general en todo el territorio y definirá los niveles que originan situaciones de emergencia.

La Norma Primaria es aquella que establece los valores de las concentraciones y períodos, máximos o mínimos permisibles de elementos; compuestos, sustancias, derivados químicos o biológicos, energías, radiaciones, vibraciones, ruidos o combinaciones de ellos, cuya presencia o carencia en el ambiente pueda constituir un riesgo para la vida o la salud de la población.

La Norma Secundaria es aquella que establece los valores de las concentraciones y períodos, máximos o mínimós permisibles de sustancias, elementos, energía o combinación de ellos, cuya presencia o carencia en el ambiente pueda constituir un riesgo para la protección o la conservación del medio ambiente, o la preservación de la naturaleza.

En todo caso, un Reglamento deberá establecer el procedimiento a seguir en la dictación de normas de calidad ambiental.

En cuanto a la Preservación de la Naturaleza y Conservación del patrimonio Ambiental el Estado administrará un Sistema Nacional de Areas Silvestre Protegidas, que incluirá los parques y reservas marinas. Todo lo cual queda también sujeto a la dictación de un Reglamento que fijará el procedimiento para su establecimiento.

Respecto a las Normas de Emisión, que son las qụe establecen la cantidad máxima permitida para un contaminante medida en el afluente de la fuente emisora, éstas se determinarán mediante decreto de la autoridad, el que señalará su ámbito de aplicación territorial.

Corresponderá a la Comisión Nacional de Medio Ambiente proponer, facilitar y coordinar la dictación de estas normas, para lo cual deberá sujetarse el reglamento que se dicte a lo dispuesto en las Normas Primarias y Secundarias.

\section{Planes de Manejo, Prevención o Descontaminación}

La ley establece en los artículos 41 al 48, diversas normas destinadas a establecer Planes de Manejo, Prevención y Descontaminación.

Para estos efectos dispone la posibilidad que la autoridad declare una zona del territorio como Zona Saturada, esto es, aquélla en que una o más normas de calidad ambiental se encuentra sobrepasada o Zona Latente, que es aquélla en que la medición de la concentración de la contaminantes en el aire, agua o suelo se sitúa entre el $80 \%$ y el $100 \%$ del valor de la respectiva norma de calidad ambiental.

Hecha tal declaración se establecerán los planes de prevención o descontaminación, los que incluirá la obligación que las actividades contaminantes a reducir sus emisiones a niveles suficientes para el cumplimiento del Plan.

\section{Responsabilidad por Daño Ambiental}

Probablemente uno de los aspectos más novedosos que introduce la ley sea la de 
responsabilidad por Daño Ambiental, definido como, toda pérdida, disminución detrimento, menoscabo significativo inferido al medio ambiente o a uno o más de sus componentes.

Así, todo el que culposa o dolosamente cause daño ambiental deberá responder de daño o perjuicio, sea que la sanción esté prevista en la ley que comentamos o en otras leyes especiales, en cuyo caso, éstas prevalecerán. Lo anterior importa establecer como criterio general la responsabilidad subjetiva, esto es, que corresponderá probar al afectado que el perjuicio fue causado con dolo o culpa.

Sin embargo, la ley presume legalmente la responsabilidad del autor del daño ambiental, si existe infracción a las normas de calidad ambiental, a las normas de emisiones, a los planes de prevención o de descontaminación, a las regulaciones especiales para los casos de emergencia ambiental o a las normas sobre protección, preservación o conservación ambientales, establecidas en la ley o en otras disposiciones legales o reglamentarias.

Lo expresado constituye un sistema de tipo mixto que se denomina de responsabilidad subjetiva con presunción legal.

En todo caso, sólo habrá lugar a indemnización si se acreditare relación de causa a efecto entre la infracción y el daño producido.

Puede demandar la reparación del medio ambiente dañado las personas naturales o jurídicas, públicas o privadas, que hayan sufrido el daño o perjuicio, las Municipalidades, en su jurisdicción, y el Estado por intermedio del Consejo de Defensa del Estado. Pero interpuesta la demanda por uno de ellos no podrán demandar los restantes, quienes sólo podrán actuar como terceros.

La interposición de esta acción no obsta a que el directamente afectado pueda ejercer la acción indemnizatoria ordinaria.

La misma ley establece el procedimiento que ha de seguirse y será competente el Juez Letrado que corresponda al lugar en que se ha producido el daño. Las causas que se sigan se tramitarán de conformidad al juicio sumario. Siendo las sentencias que se dicten apelables.

La acción ambiental y las acciones civiles emanadas del daño ambiental prescriben en cinco años, contado de la manifestación evidente del daño.

La fiscalización del cumplimiento de las normas sobre medio ambiente corresponde a los organismos del Estado que participan en el sistema de evaluación del impacto ambiental.

Sin embargo, también las municipalidades pueden participar en este control, para el solo efecto de recibir las denuncias de los ciudadanos y ponerlas en conocimiento de la. autoridad del Estado competente.

\section{Comentarios Finales}

Si bien la ley ha entrado en vigencia el pasado 9 de marzo de 1994, sus principales disposiciones no pueden llevarse a cabo mientras no se dicten los reglamentos pertinentes, y el mismo efecto tiene lugar mientras no se constituyan las autoridades que 
contempla la ley, para lo cual hay un plazo de 180 días.

Por otras parte, la obligación de reparar materialmente el daño causado al medio ambiente contemplado en el artículo $3^{2}$ de la ley, se comenzará a aplicar transcurrido que sean 90 días desde la publicación de la ley.

En todo caso, es dable esperar que en el transcurso del presente año, esta ley pueda estar rigiendo plenamente, supuesto que se hayan dictado los reglamentos y decretos correspondientes. 


\section{SENTENCIA DEL TRIBUNAL CONSTITUCIONAL Recaida en el Proyecto de Ley sobre Bases del Medio Ambiente}

Santiago, ventiocho de febrero de mil novecientos noventa y cuatro.

\section{VISTOS Y CONSIDERANDO:}

$1^{\circ}$. Que por oficio № 5318 , de 28 de enero de 1994 , el H. Senado ha enviado el proyecto de ley, aprobado por el Congreso Nacional, sobre Bases del Medio Ambiente, a fin de que este Tribunal, en conformidad a lo dispuesto en el artículo 82 , № $1^{\circ}$, de la Constitución Política de la República, ejerza el control de constitucional respecto de los artículos que en él se señalan.

El Senado aprobó los artículos 23 , inciso segundo;51; $57 ; 59 ; 60 ; 61 ; 62$, letra a) e inciso final; $63 ; 65$, inciso segundo; $66 ; 70 ; 71 ; 72 ; 73 ; 74 ; 75 ; 76 ; 77 ; 78 ; 79 ; 80 ; 81$; $82 ; 85 ; 86 ;$ y 87 , con carácter de ley orgánica constitucional.

A su vez, la Cámara de Diputados, en segundo trámite constitucional, aprobó los artículos 23 , inciso segundo; $48 ; 49 ; 51 ; 55 ; 57 ; 59 ; 60 ; 61 ; 62 ; 63 ; 65 ; 66 ; 70 ; 71 ; 72 ; 73$; $74 ; 75 ; 76 ; 77 ; 78 ; 79 ; 80 ; 81 ; 82 ; 85 ; 86 ; 87 ; 88 ; 89$, y 90 , con carácter de ley orgánica constitucional.

Según se da cuenta en el Oficio del Senado, éste, en tercer trámite constitucional aprobó con una mayoría igual o superior a los cuatro séptimos de los Senadores en ejercicio, las modificaciones introducidas por la H. Cámara de Diputados a los artículos 23 , inciso segundo; $49 ; 66 ; 71 ; 79$, letras b) y c), y 72 , inciso primero.

Por su parte las proposiciones de la Comisión Mixta, según el mismo Oficio del Senado, respecto de los artículos $55 ; 57$, inciso primero; $63 ; 83$, y 84 fueron aprobados tanto en el $\mathrm{H}$. Senado como en la H. Cámara de Diputados con las mayorías del inciso segundo del artículo 63 de la Constitución Política;

$2^{2}$. Que si se analiza con detenimiento la relación que hace el $\mathrm{H}$. Senado de los artículos aprobados con mayorías especiales se concluye que los artículos $48 ; 88 ; 89$, y 90 sólo lo fueron en la H. Cámara de Diputados, y no en el H. Senado. Igualmente, se aprecia que los artículos 62 y 65 fueron aprobados parcialmente por el $\mathrm{H}$. Senado y en su totalidad por la H. Cámara de Diputados, razón por la cual este Tribunal no se pronunciará respecto de los preceptos en que no se alcance el quórum constitucional de aprobación en ambas Cámaras, tal como se dirá en la parte pertinente de esta sentencia;

3․ Que el artículo 82, № 1을 de la Constitución Política establece que es atribución de este Tribunal: "Ejercer el control de la constitucionalidad de las leyes orgánicas constitucionales antes de su promulgación y de las leyes que interpreten algún precepto de la Constitución"; 
4․ Que, de acuerdo al considerando anterior de esta sentencia, corresponde a este Tribunal pronunciarse sobre las normas del proyecto remitido que están comprendidas dentro de las materias que el constituyente ha reservado a una ley orgánica constitucional;

52. Que las normas establecidas en los artículos 51 - salvo en la parte que dice "y la aplicación de las regulaciones especiales en caso de emergencia,"-; 61 , inciso primero; 63 , inciso segundo, y 65 , inciso segundo, del proyecto de ley remitido se encuentran comprendidas dentro de las materias que el constituyente ha reservado a la ley orgánica constitucional a que se refiere el artículo 74, inciso primero, de la Constitución Política de la República;

60. Que la norma contemplada en el inciso segundo del artículo 23 del proyecto sometido a control es propia de la ley orgánica constitucional indicada en el artículo 107 de la Constitución Política de la República;

70. Que las disposiciones contenidas en los artículos 70, inciso tercero; 72 , inciso primero; $78 ; 79 ; 81 ; 82$, y 83 del proyecto, son propias de la ley orgánica constitucional referida en el inciso primero del artículo 38 de la Constitución Política de la República;

8․ Que respecto al inciso segundo del artículo 51 del proyecto que dispone: "La interposición del reclamo no suspenderá en caso alguno los efectos del acto impugnado.", El Tribunal previene que en ningún caso se puede afectar con la disposición transcrita las funciones jurisdiccionales del juez a que se refiere el artículo 73 de la Constitución Política de la República;

$9^{\circ}$. Que respecto de las normas contempladas en los artículos 55,57 y 66 , el Tribunal no se pronuncia sobre ellas, puesto que de acuerdo al inciso segundo del artículo $5^{\circ}$ de la Ley № 18.695 , Orgánica Constitucional de Municipalidades, se dispone que todo lo relacionado con las materias vinculadas a la protección del medio ambiente son atribuciones no esenciales de las municipalidades $y$, por tanto, quedan entregadas al campo de la ley común;

10․ Que el Tribunal tampoco se pronuncia sobre las siguientes disposiciones: ar- . tículos 59; 60; 61, inciso segundo; 62, letra a) e inciso final; 63, incisos primero y tercero; 70 , incisos primero y segundo; 70 , incisos primero y segundo; $71 ; 72$, inciso segundo; $73 ; 74 ; 75 ; 76 ; 77 ; 80 ; 84 ; 85 ; 86$, y 87 , por versar sobre materias que no son propias de la ley orgánica constitucional, según se desprende de la interpretación que deriva del texto de dichos preceptos, de la naturaleza de las leyes orgánicas constitucionales dentro de nuestra normativa jurídica y del espíritu del constituyente al incorporarlas a la Carta Fundamental;

11. Que el artículo 49 del proyecto es materia de ley orgánica constitucional, y como tal ha sido aprobada por ambas ramas del Congreso Nacional, pero el precepto adolece de inconstitucionalidad por varias causales.

En efecto, el artículo 49, que constituye el Párrafo $7^{\circ}$ del título II del presente proyecto de ley, se refiere a "las Situaciones de Emergencia Ambiental". Dice su texto: "Se establecerán regulaciones especiales de carácter permanente para las emisiones, las que serán aplicadas cuando se sobrepasen los niveles de contaminación que originan situaciones de emergencia, de acuerdo a lo establecido en el artículo 32.

"Estas regulaciones especiales tendrán por objeto que los índices de calidad am- 
biental, en el área afectada, recuperen su nivel de normalidad. Para ello, establecerán emisiones totales máximas, que sólo regirán durante el período necesario para lograr dicho objeto.

"Excepcionalmente, sólo cuando resulte indispensable para recuperar los niveles de normalidad de los índices de calidad ambiental y exclusivamente por el período necesario para ello, dichas regulaciones podrán comprender restricciones totales o parciales al uso de vehículos motorizados contaminantes y prohibiciones totales o parciales de emisión a empresas, industrias, faenas o actividades que produzcan o puedan incrementar la contaminación ambiental.

"Las regulaciones especiales a que se refiere el inciso anterior, se establecerán por decreto supremo, que llevará las firmas del Ministro Secretario General de la Presidencia, del Ministro de Salud y de los ministros sectoriales correspondientes. Este decreto señalará las autoridades encargadas de su aplicación y fiscalización y establecerá las obligaciones de medición y control que correspondan.

"El procedimiento a seguir para la dictación de estas regulaciones especiales deberá ceñirse a lo dispuesto en el inciso tercero del artículo 32.";

12. Que dicho precepto vulnera la Constitución en cuanto dispone que las regulaciones especiales que se establezcan conforme al artículo 32 del mismo proyecto, por decreto supremo y de acuerdo a un reglamento, "podrán comprender restricciones totales o parciales al uso de vehículos motorizados contaminantes y prohibiciones totales o parciales de emisión a empresas, industrias, faenas o actividades que produzcan o puedan incrementar la contaminación ambiental "(inciso tercero). y la vulnera:

a) Porque según la Constitución Política en su artículo 19, № 8 , inciso segundo, que dice: "La ley podrá establecer restricciones específicas al ejercicio de determinados derechos o libertades para proteger el medio ambiente", ello es de reserva legal; es decir, es de competencia exclusiva y excluyente del legislador el establecer restricciones específicas al ejercicio de determinados derechos o libertades para proteger el medio ambiente;

b) Porque esas "restricciones" específicas la Constitución las prevé para los "estados de excepción constitucional" (artículos 39 a 41 de la Constitución Política) y no para situaciones de normalidad constitucional en las que se mueve el legislador en este proyecto, por lo cual la disposición analizada excede notoriamente la normativa fundamental (artículos $6^{\circ}$ y $7^{\circ}$, en relación con los artículos $1^{\circ}$, inciso cuarto, y $5^{\circ}$, inciso segundo, de la Constitución Política);

c) Porque al establecer el referido artículo 49 del proyecto "restricciones" totales o parciales al uso de vehículos motorizados contaminantes, infringe el artículo 19, № 24 de la Constitución, que permite que sólo la ley pueda "establecer" el modo de usar, gozar y disponer de los bienes sobre los cuales se tiene derecho de propiedad, y "establecer" limitaciones que deriven de su función social, función que comprende entre otros cuanto elija "la conservación del patrimonio ambiental" (inciso segundo). Aquí no es la "ley" la que establece las condiciones o requisitos, sino que se reenvía ello a la determinación que haga el Presidente de la República mediante un "acto administrativo reglamentario" (inciso cuarto, en relación con el artículo 32 del proyecto); ello vulnera, además, los artículos $6^{\circ}$ y $7^{\circ}$, y los artículos $1^{\circ}$, inciso cuarto, y $5^{\circ}$, inciso segundo, de la Carta Fundamental; 
d) Porque el establecer "prohibiciones totales o parciales" de emisión a empresas, industrias, faenas o actividades que produzcan o puedan incrementar la contaminación ambiental, viola el artículo 19, № 21, inciso primero, de la Constitución Política, que reconoce a todas las personas el "derecho a desarrollar cualquiera actividad económica que no sea contraria a la moral, al orden público o a la seguridad nacional, respetando las normas legales que la regulen". La regulación de la actividad referida es materia de reserva legal y el artículo 49 del referido proyecto no es precisamente quien regula el punto sino que expresamente reenvía a regulaciones dictadas por la autoridad administrativa, por medio de un reglamento administrativo; por ello mismo vulnéranse también los artículos $6^{\circ}$ y $7^{\circ}, 1^{\circ}$, inciso cuarto, y $5^{\circ}$, inciso segundo, de la Constitución;

e) Finalmente, porque al pretender establecer restricciones totales o parciales, y prohibiciones totales o parciales, al ejercicio de derechos fundamentales de las personas, se afecta el contenido esencial de ellos, lo que se encuentra expresamente prohibido por el artículo 19, № 26; de la Constitución, lo que hace que se infrinjan asimismo sus artículos $6^{\circ}$ y $7^{\circ}, 1^{\circ}$, inciso cuarto y $5^{\circ}$, inciso segundo, en relación con su artículo $19,^{\circ}$ s. 24 y 21 ;

13. Que, en consecuencia el artículo 49 del proyecto remitido es inconstitucional;

14. Que la frase "y los que establezçan las regulaciones especiales que regirán en caso de emergencia ambiental", contenida en el artículo 50 del proyecto; y la frase "y la aplicación de las regulaciones especiales en caso de emergencia," del inciso primero del artículo 51 del proyecto, son inconstitucionales como consecuencia de la inconstitucionalidad establecida en el considerando anterior;

15. Que las disposiciones a que hacen referencia los considerandos $5^{\circ}, 6^{\circ}$ y $7^{\circ}$ no contienen normas contrarias a la Constitución Política de la República y son, en consecuencia, constitucionales;

16. Que consta de autos que se ha oído, en los artículos pertinentes, previamente a la Corte Suprema de acuerdo a lo dispuesto en el inciso segundo del artículo 74 de la Constitución Política;

17. Que consta, asimismo, de autos que sobre las disposiciones sometidas a control de constitucionalidad, no se ha suscitado cuestión de constitucionalidad.

Y, VISTO, lo dispuesto en los artículos 38,63,73, 74, 82, № $1^{\circ}$ y 107 de la Constitución Política de la República, lo establecido en la Ley № 18.695, Orgánica Constitucional de Municipalidades, y lo prescrito en los artículos 34 al 37 de la Ley № 17.997, de 1981, Orgánica Constitucional de este Tribunal,

\section{SE DECLARA:}

1. Que el artículo 49 del proyecto es inconstitucional, y por tanto debe eliminarse de su texto, como asimismo el epígrafe que le precede. Que la frase "y los que establezcan las regulaciones especiales que regirán en caso de emergencia ambiental", contenida en el artículo 50 del proyecto; y la frase "y la aplicación de las regulaciones especiales en caso de emergencia," del inciso primero del artículo 51 del proyecto, también son inconstitucionales y deben eliminarse de su texto.

2. Que las normas establecidas en los artículos 23 , inciso segundo; 51 -salvo en la parte que dice "y la aplicación de las regulaciones especiales en casos de emergencia"-; 
61 , inciso primero; 63 , inciso segundo; 65 , inciso segundo; 70 , inciso tercero; 72 , inciso primero; $78 ; 79 ; 81 ; 82$, y 83 , del proyecto de ley remitido, son constitucionales.

3. Que el artículo 51 del proyecto se declara constitucional en el entendido de lo dispuesto en el considerando $8^{2}$ de esta sentencia.

4. Que no corresponde al Tribunal pronunciarse sobre los artículos $55 ; 57 ; 59 ; 60$; 61 , inciso segundo; 62 , letra a) e inciso final; 63 , incisos primero y tercero; $66 ; 70$, incisos primero y segundo; $71 ; 72$, inciso segundo; $73 ; 74 ; 75 ; 76 ; 77 ; 80 ; 84 ; 85 ; 86$, y 87 , del proyecto, por versar sobre materias que no șon propias de ley orgánica constitucional.

5. Que el Tribunal no se pronuncia sobre los artículos 48; 62 , incisos primero, segundo, letras b) y c) y tercero; 65 , inciso primero; $88 ; 89$, y 90 del proyecto, en razón de haber sido aprobados sin contar en ambas Cámaras con las mayorías especiales del artículo 63, inciso segundo, de la Constitución Política de la República.

Acordada la sentencia que declara inconstitucional el artículo 49 del proyecto y las referencias contenidas en los artículos 50 y 51 , con el voto en contra del Ministro señor Colombo, por las siguientes razones:

$\left.1^{2}\right)$ Que la Constitución Política establece un mecanismo que permite mantener un equilibrio razonado entre los derechos del estado sobre los particulares, las garantías constitucionales de éstos y el bien común.

En efecto, el artículo 19 establece los derechos y deberes constitucionales declarando en su número final que se garantiza "La seguridad de que los preceptos legales que por mandato de la Contitución regulen o complementen las garantías que ésta establece o que las limiten en los casos en que ella lo autoriza, no podrán afectar los derechos en su esencia, ni imponer condiciones, tributos o requisitos que impidan su libre ejercicio". El artículo $1^{2}$ establece como deber imperativo del Estado la promoción del bien común.

$2^{\circ}$ ) Que para el ejercicio de la soberanía que resida esencialmente en la nación, la Carta Fundamental establece tres funciones públicas claramente definidas que ejercen preferentemente los poderes públicos consagrados por sus disposiciones.

En lo que interesa para esta sentencia, la función legislativa la ejerce en lo fundamental el Congreso Nacional con participación activa del poder Ejecutivo. Su constitucionalidad, interpretación y aplicación le corresponde a los órganos jurisdiccionales consagrados por los Capítulos VI y VII de la Constitución Política.

Las materias propias de ley están establecidas por el artículo 60, y entre ellas destacan las que deben ser materia de leyes orgánicas constitucionales.

$3^{2}$ ) Que el gobierno y la administración del Estado le corresponden al Presidente de la República que como lo señala el artículo 24 "es el Jefe del Estado".

La Constitución le ha entregado atribuciones generales, en diversas disposiciones constitucionales y legales y especiales en el artículo 32.

Entre ellas destaca su potestad reglamentaria.

$\left.4^{\circ}\right)$ Que la Constitución Política consagra en sus artículos 39 a 41 los estados de excepción constitucional regulados por la ley orgánica constitucional № 18.415, de 14 
de junio de 1985.

En opinión del Ministro disidente las situaciones previstas por la ley sometida a control de este Tribunal no quedan comprendidas en los casos regulados por el artículo 40 de la Carta Fundamental. Ello significa que para corregir las alteraciones ambientales que puedan afectar gravemente a los habitantes de Chile, no puede hacerse uso de las facultades que al Presidente de la República de da la normativa sobre estados de exepción a menos qụe ello se transforme por su magnitud en calamidad pública.

$5^{\circ}$ ) Que la ley sometida al control constitucional de este Tribunal, que en cuanto al contenido del artículo 49 tiene el rango de ley orgánica constitucional, establece regulaciones especiales de carácter permanente para las emisiones, con el objeto de recuperar los índices normales que miden la calidạd ambiental.

Esta ley establece la facultad de restringir determinadas garantías constitucionales cuando ello resulta indispensable para recuperar los niveles de normalidad y exclusivamente por el período necesario para ello.

Puesta la situación ambiental en los casos previstos taxativamente por la ley, se faculta al Presidente de la República para decretar las medidas que la ley contempla, entre ellas la restricción vehicular y la prohibición de funcionamiento de empresas o industrias constaminantes.

La ley orgánica contempla acciones jurisdiccionales para que los afectàdos por alguna de las disposiciones administrativas, puedan obtener la solución de su conflicto por sentencia de los tribunales competentes.

$6^{\circ}$ ) Que si bien es efectivo que las medidas antes señaladas podrían eventualmente traducirse en una limitación al ejercicio de las garantías constitucionales contempladas especialmente en los $\mathrm{N}^{\circ} \mathrm{s}$. 21, 23 y 24 del artículo 19, no es menos cierto que ello se hace con el objeto de lograr el bien común, deber de la autoridad, como lo señala el artículo $1^{\circ}$ de la Carta Fundamental.

A propósito de lo expuesto debe tenerse presente que la Constitución tàmbién garantiza a los habitantes en su $\mathrm{N}^{2} 8$ del artículo citado, el derecho a vivir en un medio ambiente libre de contaminación, siendo deber del Estado velar para que este derecho no sea afectado, tutelando la perservación de la naturaleza.

Esta ley precisamente contempla disposiciones tendientes a preservar el medio ambiente para lo cual, de acuerdo al mandato constitucional, establece la posibilidad de decretar restricciones específicas al ejercicio de determinados derechos o libertades.

$\left.7^{\circ}\right)$ Que los artículos 6ํㅜ y $7^{\circ}$ de la Constitución Política establecen que los órganos del Estado deben someter su acción a la Constitución y a las normas dictadas conforme a ella y que sólo en ese ámbito actúan válidamente.

El inciso segundo del artículo $7^{\circ}$ establece que ninguna autoridad o persona pueden atribuirse, ni aun a pretexto de circunstancias extraordinarias, otra autoridad o derechos que los que expresamente se le hayan conferido en virtud de la Constitución o las leyes.

$8^{\circ}$ ) Que el Ministro disidente estima que el artículo 49 se ajusta a la normativa constitucional y que para seguridad de los afectados contiene los recursos jurisdiccionales necesarios para evitar que el Poder Ejecutivo pueda vulnerar garantías constituciona- 
les ejerciendo las atribuciones que la ley en consulta le confiere.

Que los Ministros señores Aburto, Jiménez y Colombo no emiten pronunciamiento sobre el contenido del artículo 32, por estimarlo materia de ley común.

El Ministro señor Jordán y el abogado integrante don Eduardo Soto Kloss estiman que al referirse el artículo 49 consultado al artículo 32, el tribunal debe también pronunciarse sobre él ya que ello significa que el artículo referido es traído, insertado e incluido en el artículo 49.

El artículo 32 dice: "Mediante decreto supremo, que llevará las firmas del Ministro Secretario General de la Presidencia y del Ministro de Salud, se promulgarán las normas primarias de calidad ambiental. Estas normas serán de aplicación general en todo el territorio de la República y definirá los niveles que se originan situaciones de emergencia.

"Mediante decreto supremo que llevará las firmas del Ministro Secretario General de la Presidencia y del ministro competente según la materia de que se trate, se promulgarán las normas secundarias de calidad ambiental.

"Un reglamento establecerá el procedimiento a seguir para la dictación de normas de calidad ambiental, que considerará a lo menos las siguientes etapas: análisis técnico y económico, desarrollo de estudios científicos, consultas a organismos competentes, públicos y privados, análisis de las observaciones formuladas y una adecuada publicidad. Establecerá además los plazos y formalidades que se requieren para dar cumplimiento a lo dispuesto en este artículo y los criterios para revisar las normas vigentes.

"Toda norma de calidad ambiental será revisada por la Comisión Nacional del Medio Ambiente a lo menos cada cinco años, aplicando el mismo procedimiento antes señalado.

"La coordinación del proceso de generación de las normas de calidad ambiental, y la determinación de los programas y plazos de cumplimiento de las mismas, corresponderá a la Comisión Nacional del Medio Ambiente.";

Que, es sabido que la regulación del ejercicio de los derechos fundamentales ha sido entregada -excepción hecha del derecho de reunión en plazas, calles y demás lugares de uso público (artículo 19, № 13, inciso segundo, de la Constitución)- a la reserva del legislador, en cuanto es éste el órgano estatal competente para dictar normas que permitan su más adecuada realización por sus titulares. Y esa regulación legislativa incluso la Constitución la condiciona en su juricidad al hecho de no "afectar los derechos en su esencia" (artículo 19, № 26). Pero hay más: a fin de asegurar efectivamente que sea el legislador quien determine esa regulación, le prohíbe expresamente que delegue atribuciones legislativas en tal materia, de tal manera que jamás puede el Presidente de lá República -en tal caso a través de decreto con fuerza de ley- intervenir en la regulación del ejercicio de los derechos fundamentales (artículos 61, inciso segundo, de la Constitución Política).

Si, como se advierte, ni siquiera puede por Decreto con Fuerza de Ley intervenir el Presidente de la República en la regulación de los derechos fundamentales por estarle expresamente prohibida tal posibilidad, mucho menos podrá intervenir por la vía simplemente reglamentaria mediante una mera remisión que le haga el legislador, pues ello además de infringir claramente las competencias que ha establecido el constituyente sig- 
nificaría un verdadero fraude a la Constitución, lo que debe declararse perentoriamente inadmisible; más aún si se considera la notoria discrecionalidad administrativa que ello conlleva y en una materia ostensiblemente delicada tanto respecto de los derechos de las personas como respecto de la actividad económica del país. Por estas razones estiman que el artículo 32 del proyecto es inconstitucional;

Que el Ministro señor Jiménez considera que el artículo 32 del proyecto en análisis a que se refiere la disposición del artículo 49 consultado versa sobre materias propias de una ley ordinaria o común y, en consecuencia, no corresponde a este Tribunal pronunciarse sobre su contenido, no obstante estimar que de haber sido dicha disposición de naturaleza orgánica constitucional debería haber sido sometido a la potestad reglamentaria del Presidente de la República, a través de los decretos supremos que contempla la dictación de las normas sobre calidad ambiental, materia propia de reserva legal según nuestra Carta Fundamental.

El Ministro señor Colombo disiente en cuanto el Tribunal no se pronuncia respecto del artículo 61, inciso segundo, pues considera que dicho precepto que establece: "En los casos en que el juez competente corresponda a lugares de asientos de Corte, en que ejerza jurisdicción civil más de un juez letrado, deberá cumplirse con lo dispuesto en el artículo 176 del Código Orgánico de Tribunales", es materia de ley orgánica constitucional, y además, sostiene:

1. Que en relación al control de constitucionalidad de esta disposición, debe tenerse presente que la jurisdicción es la facultad genérica que tienen todos los tribunales de la República para resolver conflictos de intereses de relevancia jurídica y que se encuentra expresamente reconocida por el artículo 73 de la Carta Fundamental. La competencia es el mecanismo de distribución de la jurisdicción entre los distintos tribunales, y la define el artículo 108 del Código Orgánico de Tribunales, como "la facultad que tiene cada juez o tribunal para conocer de los negocios que la ley ha colocado dentro de la esfera de sus atribuciones".

Nuestro sistema procesal, contempla tres rangos de normas para llegar a precisar el tribunal competente que radicará el conocimiento del asunto y posteriormente lo resolverá con efecto de cosa juzgada.

Las primeras establecen la competencia absoluta, a base de los factores materia, cuantía y fuero y permiten determinar la clase de tribunal que debe intervenir, o, si dentro de esa clase existieran diversas jerarquías, también ella será fijada. De su parte, las reglas de competencia relativa se basan en el factor territorio y se aplican cuando existe más de un tribunal absolutamente competente. Mediante ellas se determinará cuál de los tribunales de similar competencia absoluta es el que debe conocer. Finalmente, si aplicadas las reglas de competencia absoluta y relativa, en el lugar existe más de un tribunal de similar competencia, se aplicarán las reglas sobre distribución de causas, de tal manera, de poder llegar finalmente al tribunal habilitado por la ley para el conocimiento y resolución del conflicto sometido a la jurisdicción;

2. Que el artículo 109 del Código Orgánico de Tribunales, contempla la regla general de la competencia denominada de la radicación o fijeza, en virtud de la cual "Radicado con arreglo a la ley el conocimiento de un negocio ante tribunal competente, no se alterará esta competencia por causa sobreviniente".

Para que opere esta regla deben concurrir dos elementos: en primer término que 
el tribunal tenga competencia y en segundo lugar que la radicación se haga conforme a la ley.

El contenido de esta regla de competencia constituye presupuesto básico para que el proceso que se instruye sea "debido". Sin él no se puede llegar al efecto de cosa juzgada real. En tal contexto resulta claro que toda norma que incida en la fijación de atribuciones de los tribunales, debe quedar comprendida en el ámbito de las leyes sobre organización y atribuciones de los tribunales, que tienen el rango de orgánicas constitucionales al tenor de lo previsto por el artículo 74 de la Carta Fundamental;

3. Que el artículo 74 de la Constitución Política establece que una ley orgánica constitucional determinará la organización y atribuciones de los tribunales que fueren necesarios para la pronta y cumplida administración de justicia.

En la actualidad y de acuerdo con lo previsto por la disposición quinta transitoria de la Constitución "Se entenderá que las leyes actualmente en vigor sobre materias que conforme a esta Constitución deben ser objeto de leyes orgánicas constitucionales o aprobadas con quórum calificado, cumplen estos requisitos y seguirán aplicándose en lo que no sean contrarias a la Constitución, mientras no se dicten los correspondientes cuerpos legales". Esta es la situación en que se encuentra el Código Orgánico de Tribunales, en cuanto se refiere a normas relativas a la organización y atribuciones de los tribunales de justicia.

4. Que por su parte, el artículo 60 de la Constitución establece las materias que son propias de la ley, señalado como tales, en su número 1, a "Las que en virtud de la Constitución deben ser objeto de leyes orgánicas constitucionales", y, en lo que interesa para esta sentencia, a las que contempla el número 3 "Las que son objeto de codificación, sea civil, comercial, procesal, penal u otra".

Al tenor de las consideraciones precedentes y disposiciones citadas, lo que debe resolverse por este Tribunal, es si las reglas sobre distribución de causas contenidas en el artículo 61, inciso segundo, del proyecto quedan incluidas en el número 1 del citado artículo 60 en concordancia con el artículo 74 de la Constitución o si son objeto de ley común;

6. Que teniendo en cuenta que las normas sobre atribuciones de los tribunales deben aplicarse desde la formación del proceso y hasta la precisión total del tribunal que debe intervenir en su solución, debe concluirse que las reglas que se refieren a la distribución de causas quedan incluidas entre aquellas que se refieren a la organización de los tribunales de justicia.

Refuerza esta conclusión el tenor literal del artículo 74 de la Carta Fundamental, que ordena al legislador la dictación de una ley que contenga las normas sobre organización y atribuciones de los tribunales.

En mérito de las consideraciones precedentes, este Tribunal debe emitir pronunciamiento sobre el contenido del inciso segundo del artículo 61 del proyecto.

Acordada la sentencia con el voto en contra del Ministro sẹ̃or Servando Jordán y del abogado integrante don Eduardo Soto Kloss, quienes estuvieron por afirmar que las frases primera y segunda del artículo 55 del proyecto son materia de ley orgánica constitucional. 
Sostienen ello fundados en que la frase segunda, cuyo texto es el siguiente "Deducida demanda por alguno de los titulares señalados, no podrán interponerla los restantes, lo que no obsta a su derecho a intervenir como terceros.", incide de lleno en las "atribuciones de los tribunales" a que se refiere el artículo 74 de la Constitución y que ésta exige que sea regulada por este tipo de leyes (inciso segundo), puesto que impide a los tribunales aceptar a conocer "demandas" en la materia que regula este artículo 55 del proyecto cuando ya la hayan deducido los sujetos que indica su inciso primero.

Además, sostienen que dicha frase segunda vulnera de manera muy clara la Constitución en cuanto tal disposición impide y cercena el ejercicio del derecho fundamental reconocido a toda persona para ocurrir a la Justicia en demanda de sus derechos (artículo 19, № 3, inciso primero, de la Constitución Política, y además vulnera el artículo 19, № 26, de la misma Carta Fundamental pues impone una prohibición que afecta la "esencia" del referido derecho fundamental, ya que se permite al afectado su intervención solamente como tercero y no como demandante. Ello significa, además, vulnerar el derecho a la igualdad ante la ley (artículo 19, № 2, de la Constitución), pues incurre en una discriminación carente de toda razonabilidad, y también el artículo $5 \%$, inciso segundo, de la Carta Fundamental, desde que el legislador infringe por esta frase segunda analizada su deber de respetar los derechos esenciales que emanan de la naturaleza humana como es el derecho a ocurrir ante la Justicia, sin trabas ni limitaciones, ni mucho menos prohibiciones, como en este caso en que se cercena su legitimación activa como demandante no obstante tener sus derechos afectados por la acción de un tercero. Tal prohibición, sostienen los disidentes, es enteramente inconstitucional.

Acordada la sentencia que declara no corresponderle al Tribunal pronunciarse sobre el artículo 57 del proyecto, con el voto en contra del Ministro señor Servando Jordán y del abogado integrante don Eduardo Soto Kloss, quienes estiman que se trata de un precepto con carácter de ley orgánica constitucional, por cuanto al otorgar competencia al juez a que se refiere el artículo 61 del proyecto, para imponer la sanciones que este artículo 57 establece, se está afectando las "atribuciones de los tribunales de justicia y conforme con lo dispuesto por el artículo 74 de la Constitución Política, ello es materia de ley orgánica constitucional. Lo mismo debe decirse de los artículos 58, 59 y 60 de este proyecto.

Acordada la sentencia que declaró constitucional el inciso segundo del artículo 65 del proyecto, con el voto en contra del abogado integrante don Eduardo Soto Kloss, quien estuvo por declararlo inconstitucional en lo referente a la exigencia para recurrir ante la Justicia de una "previa consignación equivalente al $10 \%$ del valor de la multa aplicada", multa que según el inciso primero de la misma disposición puede ascender "hasta quinientas unidades tributarias mensuales", impuesta por la autoridad administrativa (Comisión Nacional o Regional del Medio Ambiente).

Sostiene la inconstitucionalidad de la exigencia de la previa consignación de una suma de dinero equivalente a un porcentaje de la sanción de multa impuesta por una autoridad administrativa, por cuanto ello vulnera de modo flagrante el derecho fundamental del afectado a la "igual protección de la ley en el ejercicio de sus derechos" (artículo 19, № 3, de la Constitución), derecho que implica en sí mismo el derecho fundamental del acceso a la justicia y el derecho fundamental a una efectiva tutela judicial por parte de los tribunales.

En efecto, el imponer la obligación de pagar una suma de dinero sea el total, sea 
como en este caso el equivalente a un porcentaje de la sanción de multa impuesta por vía administrativa, para poder el afectado reclamar de ella, es un impedimento para el ejercicio de su derecho a recurrir al juez, que incluso puede afectar su derecho en su escencia (artículo 19, № 26, de la Constitución); no puede escaparse que este requisito impuesto para abrir la vía judicial, es una exigencia que sólo tiene por objeto y finalidad precisamente entrabar y obstaculizar el ejercicio de este derecho.

Ello vulnera, además, el artículo $5^{\circ}$ de la Constitución, que impone una expresa obligación a todo órgano del Estado, incluido obviamente el legislador, de respetar y promover los derechos escenciales que emanan de la naturaleza humana, siendo el derecho del acceso a la justicia uno de los más inequívocos derechos naturales del ser humano, como es el derecho a la defensa ante un juez, es decir ante un tercero independiente e imparcial. Y tanto más grave aparece esta vulneración cuando en el artículo 65 del proyecto en análisis (inciso primero) no hay norma legal alguna que prevea el debido procedimiento administrativo para la elaboración de de esos actos administrativos sancionadores (artículo $7^{\circ}$, inciso primero, y $60, N^{\circ} 18$, de la Constitución), requisito escencial para que esas sanciones aparezcan revestidas de algún viso de juridicidad, en cuanto se respeten los principios elementales de la justicia natural (imparcialidad, contradictoriedad verdadera y leal, publicidad).

Además, este gravamen conlleva el atentar en contra del derecho a la "igualdad ante la ley" (artículo 19, № 2, de la Constitución) puesto que una tal exigencia de pagar parte de la multa impuesta por vía administrativa para tener la posibilidad de reclamar de ella ante la Justicia, significa un privilegio para la autoridad administrativa sin fundamento constitucional, y que, por el contrario, no es sino una discriminación arbitraria. Un tal "privilegio" no cuadra con la Constitución desde que ésta dispone de modo rotundo y sin tapujos que "En Chile no hay persona ni grupo privilegiados" (inciso primero), y ciertamente que lo es quien sin ser juez se ve provisto con la garantía de que sus actos no pueden ser controvertidos ante la Justicia sin que se pague previamente la multa, o parte de ella, que unilateralmente él mismo ha impuesto, y que agravia y puede hacerlo gravemente a un tercero afecto por ella. Ello implica una discriminación "arbitraria", desde que no aparece fundada racionalmente puesto que no constituye precisamente signo de racionalidad impedir el ejercicio de los derechos fundamenteles, y sobre todo uno de tal relevancia como es el acceder a la justicia en demanda de protección o amparo frente al agravio de un tercero, quienquiera sea éste, aun si el propio Estado.

Por otra parte, de la propia Constitución resulta, conforme con sus artículos 1으, inciso cuarto, y $5^{\circ}$, inciso segundo, que es deber del Estado y de cada uno de sus órganos -incluido ciertamente el legislador- de promover el ejercicio de los derechos y no obstaculizarlos, y de remover los obstáculos que impiden a las personas su libertad o igualdad, o el pleno desarrollo de su personalidad, a fin de permitir su mayor realización, que es justamente la promoción del bien común, que es el fin mismo del Estado, No se olvide que el bien común reside en las condiciones de ejercicio de las libertades naturales que son indispensables para el desarrollo de la vocación humana.

El "solve et repete", fatídico resabio de épocas estatistas, irrespetuosas de los derechos de las personas que plantea el inciso segundo del artículo 65 del proyecto referido, vulnera precisa y cabalmente este deber impuesto también al legislador por la propia Constitución, en su afán de hacer realidad la primacía de la persona y el carácter servicial del Estado. Y lo vulnera cualquiera sea el monto -si poco o mucho- del valor que im- 
ponga como requisito para ocurrir a la Justicia en reclamo de los derechos de las personas.

No está de más señalar:

a) Que la Corte Constitucional Italianá hace ya más de treinta años ha declarado inconstitucional el "solve et repete" (sentencia del 31 de diciembre de 1961, reafirmada poco después el 30 de diciembre de 1961) por ser contrario precisamente el "derecho a la igưaldad", que la Constitución de 1947 (artículo $3^{\circ}$ ) reconoce a todos los ciudadanos (pueden verse los comentarios de G. Treves y C. Esposito en Giurisprudenza Constitucionales, 1961, pp. 139 y ss.);

b) Que en España fue suprimido este artificio antilibertario por la ley de la Jurisdicción Contencioso-Administrativa (27 de diciembre de 1956) conforme al correcto sentido que la jurisprudencia fue dando a su artículo 57.2 letra e) (véase J. González Pérez, "El derecho a la tutela jurisdiccional". Civitas, Madrid, 1994, p. 79: "ha quedado definitivamente superado este gravísimo obstáculo a la Justicia");

c) Que la Declaraçión Universal de los Derechos Humanos, adoptada el 10 de diciembre de 1948 , declara en su artículo $8^{\circ}$ que "Toda persona tiene derecho a un recurso efectivo ante los tribunales nacionales competentes, que la ampare contra actos que violen sus derechos fundamentales reconocidos por la constitución o la ley", y resulta obvio que exigencias económicas para acudir a la jurisdicción como es el pago previo de la multa, o un equivalente a un porcentaje de ella, que impone unilateralmente la Administración, vulnera el citado artículo $8^{\circ}$ y hace ilusoria tal efectividad;

d) Que el Pacto Internacional de Derechos Civiles y Políticos, (Organización de las Naciones Unidas) de 16 dẹ diciembre de 1966, promulgado por Decreto Supremo del Ministerio de Rélaciones Exteriores No778 (Diario Oficial del 29 de abril de 1989) en su artículo 26 reconoce a toda persona la igualdad ante la ley "y el derecho sin discriminación a igual protección de la ley", debiendo la ley prohibir toda discriminación y proveer los medios para garantizar la "protección igual y efectiva" frente a cualquiera discriminación; y por últịmo,

e) Que la Convención Americana de Derechos Humanos (Pacto de San José, de 1969) en su artículo 8으. № 1 , referente a "garantías judiciales", también reconoce el derecho furdamental de toda persona a ser oída por un juez o tribunal, lo que resulta incompatible con el mecanismo del previo pago de un porcentaje de la multa administrativa que precisamente se trata de reclamar, exigencia que obstaculiza, limita, restringe e incluso impide el acceso libre e igualitario a la justicia.

Por las consideraciones expuestas, el inciso segundo del artículo 65 del proyecto de ley sobre Bases del Medio Ambiente es sobradamente inconstitucional.

El Ministro señor Jiménez previene que aceptando los conceptos de la sentencia no comparte lo establecido en su considerando 12 , letra b).

Con la prevención del abogado integrante don Eduardo Soto Kloss quien estuvo por declarar inconstitucional el artículo 13 del proyecto en cuanto éște remite a un reglamento la dictación de las normas por las cuales se ha de elaborar por los interesados los estudios de impacto ambiental y de calificarlo la Comisión Nacional o Regional de Medio Ambiente, ya que tratándose del derecho a realizar cualquiera actividad económica su ejercicio es materia de regulación "legal" y jamás reglamentaria (artículo 19, № 
21, inciso primero, de la Constitución); como asimismo el citado artículo 13 y el artículo 14 en cuanto remiten a un reglamento para que éste establezca el "procedimiento administrativo" para la tramitación de los estudios referidos, lo que infringe palmariamente el artículo $7^{\circ}$ de la Carta Fundamental el cual, junto con el artículo 60, № 18 de ella, establece la reserva legal de la materia. Del mismo modo, resulta inconstitucional el artículo 35 , inciso final, de este proyecto, que remite al reglamento el establecimiento de normas sobre "requisitos, plazos y limitaciones de aplicación general que se deberán cumplir para gozar de las franquicias, ejercer los derechos a dar cumplimiento a las obligaciones y cargas a que se refiere su artículo $1^{\circ}$, materias todas que son de manifiesta reserva legal y jamás de competencia de un órgano administrativo (véase artículo 62, incisos segundo, y cuarto №1, de la Constitución).

Redactó la sentencia el señor abogado integrante don Eduardo Soto Kloss; las disidencias el Ministro señor Juan Colombo Campbell y el abogado integrante don Eduardo Soto Kloss y las prevenciones sus autores.

Devuélvase el proyecto al Honorable Senado, rubricado en cada una de sus hojas por el Secretario del Tribunal, oficiándose. Regístrese, déjese fotocopia del proyecto y archívese. Rol № 185.

Se certifica que el Ministro señor Servando Jordán López, concurrió a la vista de la causa y al acuerdo del fallo, pero no firma por estar ausente en comisión de servicio dispuesta por la Excma. Corte Suprema.

Pronunciada por el Excmo. Tribunal Constitucional, integrado por su Presidente don Marcos Aburto Ochoa, y los Ministros señores Manuel Jiménez Bulnes, Servando Jordán López, Juan Colombo Campbell y el abogado integrante don Eduardo Soto Kloss. Autoriza el Secretario del Tribunal Constitucional, don Rafael Larraín Cruz. 